\title{
Online Course on the History of Algorithms
}

\author{
Alfonsa García López, Rosa María Pinero Fernández, and Puerto Ramírez Fernández
}

\begin{abstract}
This paper describes the objectives, content, learning methodology, and results of an online course on the History of Algorithms for engineering students at Polytechnic University of Madrid. This course is conducted in a virtual environment based on Moodle, with a student-centered educational model, which includes a detailed planning of learning activities. Our experience indicates that this subject is highly motivating for students and the virtual environment facilitates competencies development.
\end{abstract}

Index Terms-E-learning, history of algorithms, studentcentered learning.

\section{INTRODUCTION}

A LGORITHMIC Science, which can be defined as the science of arithmetic and algebraic calculation, is concerned with inventing and analysing algorithms. To a large extent, it forms the foundation of Computer Science and sets the limits between the problems that can and cannot be solved by a computer.

Although algorithms are independent of the computer and existed before it was invented, the study of algorithms came to the fore halfway through the $20^{\text {th }}$ century with the birth of Computer Science.

It was not until the $20^{\text {th }}$ century that an exact formulation of the concept of the algorithm came about through the idea of Turing machine (1937). It was also in the last century when human brain activity was begun to be seen as a defined sequence of operations and it was assumed that a large part of this activity was algorithmic.

In one way, algorithms are an inherited legacy of the human race and a study of their history brings about a deeper knowledge of their techniques. It also develops the ability to invent new algorithms and improve others, all of which contributes to the development of generic competencies, such as "Problem Solving", and specific Engineering competencies like the "Ability to analyze, design, construct and maintain applications in a robust, secure and efficient manner".

The study of the History of Algorithms is intrinsically interesting. On the one hand there is the contribution of historical aspects to the nature of discoveries and the forming of concepts, while on the other hand, there is knowledge of the evolution of science and how it relates to and interacts with different theories. In this respect, we can subscribe to
Gerald Holton's quote taken from the "Report on General Education in a Free Society" [1]: "The emphasis on historical development in this course is in no sense to constitutive merely a humanistic garnishing of its factual material. On the contrary, it is introduced to illuminate and vitalize the content with which it is integrated. The attempt should be made in this course to teach science as part of the total intellectual and historical process, of which, in fact, it has always been an important part. The student should gain thereby and insight into the principles of science.... and appreciation of the values of the scientific enterprise, and he should also learn much of the subject matter..."

Books can be found that are devoted to the History of Algorithms, even ones intended for general interest [2]. However, it is not easy to find a university course where this discipline can be studied. It is possible to find on the History of Computing (although not very many). As pointed out in [3], in 1991 the Polytechnic University of Catalonia offered a course on the History of Computing for the first time in Spain. In [4] there is a list of Spanish universities offering this discipline. Regarding the rest of the world, the list compiled by the University of Warwick [5] is interesting as it attempts to list all the universities in the world that offer a course on the History of Computing. However, the History of Algorithms is more extensive and has its roots in the dawn of civilization when it became necessary to invent algorithms to solve such basic problems as counting, calculating or measuring. Parts of the History of Algorithms are also included in subjects such as the History of Engineering at the Autonomous University of Madrid [6] or the History of Mathematics at the Complutense University of Madrid [7].

Any engineer needs to formulate algorithms to solve problems, and a knowledge of the history of a discipline is an important component if it is to be mastered. For this reason, we decided to offer a free choice subject on the History of Algorithms (HA).

The spirit of free choice means that students can freely configure a part of their curriculum and complete their education with subjects that are of their interest. But this freedom is often limited by the compatibilities of the timetable and the ease of access to the physical place where the subject is taught. However, the new technologies and the online learning environments that the distance-learning universities have been using for years are now letting the on-campus universities widen their educational choice by eliminating the barriers of physical distance and time. This is why, currently, many on-campus universities are offering a range of online subjects that is linked to the changes in methodology (see [8]). The choice offered even includes traditional face-to-face contexts, such as the teaching of mathematics (see [9]). 
Our HA subject is included in Polytechnic University's Global Online Free Choice Offering [10], together with over one hundred and thirty subjects that are offered to supplement learning in Engineering and Architecture studies and embrace a wide variety of materials, which, among others, include Science, Technology, Management, History of Art and Art and Philosophy. The subjects are generally taught in a virtual learning environment, which usually lets knowledge be attained without any need to coincide in time and place with the teacher, and from any computer connected to the Internet. A choice can be made between e-learning modalities (totally distance-learning) and b-learning (with some face-toface activities).

Specifically, the HA is taught through e-learning, with material specially designed to be used on the Institutional Online Environment [11], which is based on Moodle (Modular Object-Orinted Dinamic Learning Environmet). Some of the advantages of this tool are:

1) Ease of access, as it uses free open source code.

2) Simple to use, as it is very intuitive.

3) A variety of resources for managing activities.

4) Institutional back-up.

5) Widely-used, which means advantage can be taken of other experiences (see [11], [12], [13], [14]).

The online modality is particularly suitable for informative subjects but aspires to be sufficiently rigorous, in line with texts such as [2], [3], [15] or [16]. It also seizes the opportunity to present students with the fascinating historical fact that in the first third of the $20^{\text {th }}$ century, due to motives that are intrinsic to Mathematics, a group of cutting-edge scientists made an extraordinarily rigorous study of the basic notions of what could be computed (or achievable through algorithms). Even more important is that they set some basic boundaries that cannot be crossed by any device or computational formalism. And all this before the advent of what might be called the first computers! This subject affords the opportunity to present some very basic ideas on the Theory of Computability that are not covered by other subjects.

\section{LAUnching The ONLine Course}

The starting-point was the prior experience of the 2007-2009 HA courses taught face-to-face as part of the framework of a UPM qualification, Expert in Algorithms to Business and Industry (see [17]). We therefore decided to open the subject up to other students and offer it in e-learning format. In this form, the HA subject was implemented in the 2009-10 course with over 30 places being made available, all of which were completely taken up by students enrolled in the different branches of Engineering.

The estimated student workload for the subject is for 75 to 80 hour, spread over the different planned learning activities.

In order to design the course, plans were made along the lines of what is described in [12] with the following stages:

1) A definition of competencies and learning outcomes.

2) Designing a feasible learning activities programme that would enable the expected outcomes to be achieved.

3) Planning a delivery schedule.
4) Planning an online continuous assessment model that would strengthen the training role of the assessment by introducing immediate feedback mechanisms.

5) Establishing a quality protocol to include systematic data collection to improve the process.

\section{COMPETENCIES}

The specific competency of the HA subject is: To acquire a knowledge of current algorithm techniques based on their historical precedents and reach an understanding of how certain problems were dealt with historically, from different points of view, combining known techniques and algorithms.

In addition, the subject is designed to foster the development of the following generic competencies:

1) Self learning.

2) Use of technology.

3) Problem-solving.

4) Ability to analyze and synthesize

5) Writing scientific documents.

The following specific learning outcomes have been set:

1) To be aware of the origin of the word algorithm and value the importance of the work of Musa AlKhwarizmi.

2) To identify the basic characteristics of an algorithm.

3) To formulate algorithms to solve simple problems and identify when an algorithm is well-formulated.

4) To distinguish between the "formal verification of an algorithm" and "testing", as well as between "there is no known algorithm to solve a problem" and "the problem cannot be solved by algorithms".

5) To evaluate the contributions of certain major individuals in the history of algorithms and place them in time.

6) To know the characteristics of some ancient numbering systems and the corresponding algorithms used to carry out basic arithmetical procedures.

7) To analyze how the "automation of calculation" and the "mechanisation of deductive processes" evolved historically.

8) To analyze the historical evolution, before and after the advent of computers, of different algorithms for solving certain problems (factoring integer numbers, solving equations, cryptography, ordering ...).

9) Understanding the problem of the consistency of mathematics that arose in the $19^{\text {th }}-20^{\text {th }}$ centuries. In particular, the problems set by Hilbert regarding the completeness, consistency and decidability of deductive systems and Gödel, Turing and Church's responses to these problems.

10) To evaluate the historical context in which the Theory of Computability arose.

11) To develop the rudiments of the Theory of Computability based on a current programming language.

12) To understand the undecidability of the halting problem and to know other undecidable problems.

13) To be familiar with the notion of Turing machine and evaluate his influence on the computer architecture proposed by Von Newman. 
14) To analyze the role of programming languages to express algorithms and communicate with computers.

15) To understand the notion of machine language and the need for abstraction that leads to high level language.

16) To compare different programming paradigms and their evolution throughout history.

17) To understand the essential ideas behind the analysis of algorithms and the concepts of efficiency and exactitude.

18) To become familiar with some rudiments regarding the types of complexity and, as a result, with algorithms that are considered tractable and intractable. To understand the $\mathrm{P}$ versus NP question.

19) To evaluate the historical importance of determined cryptographic algorithms, with examples like the "Enigma Machine".

20) To understand the importance of the computational cost of factoring algorithms in present-day public key cryptography and particularly with reference to the RSA algorithm.

21) To appreciate the relevance of Grover and Shor's quantum algorithms and to be aware of the contribution of quantum cryptography.

Although it is hoped to attain these e-learning outcomes on a very basic level, the programme is ambitious, for which reason we have striven to present the content in an understandable and easy way by supplementing the historical point of view with programming ideas that are more modern and familiar to the student, which strengthens their educational worth. The course content has been organised into the following topics:

1) Algorithms prior to the advent of computers.

2) The birth of Computability Theory.

3) From algorithms to programs.

4) Improving efficiency: Different algorithms for the same problem.

For topic 4 some problems were chosen, like the problem of secret communication or ordering lists, bearing in mind the attractive range of algorithms developed for these problems throughout history.

The learning outcomes for 4, 5 and 8 are transversal and deal with different topics. Topic 1 is specifically dealt with by outcomes $1,2,3,6$ and 7, topic 2 by the outcomes of 9 to 13 , topic 3 by 14 to 16 and topic 4 by 17 to 21 .

\section{METHODOLOGY}

The new technologies allow new ways of learning, placing more importance on the student and where the teacher has a guiding role in the building of knowledge.

The HA subject is entirely taught through e-learning, with the support of Moodle. With the purpose of organising the use of all the different teaching resources, students have a subject schedule, and for each topic a Learning Guide that sets out the:

1) Topic learning outcomes.

2) Material to be used and references.

3) Specific instructions on the activities to be carried out.

A News Forum has been created as a communication tool between teachers and students as a way of reminding students
TABLE I

GUIDED PROJECTS

\begin{tabular}{|l|l|}
\hline GP 1.1 & Ancient numbering systems \\
\hline GP 1.2 & Mechanisation of calculation \\
\hline GP 1.3 & Problems with algorithmic solutions \\
\hline GP 2.1 & Turing test \\
\hline GP 2.2 & Turing machine \\
\hline GP 2.3 & Contributions and limitations of ENIAC \\
\hline GP 3.1 & Biographies of important people \\
\hline GP 3.2 & History of a programming language \\
\hline GP 4.1 & Enigma machine \\
\hline GP 4.2 & Historical view of ordering and search algorithms \\
\hline GP 4.3 & P and NP complexity problems \\
\hline GP 4.4 & Quantum algorithms and cryptography \\
\hline
\end{tabular}

of the different activities. Other tools have been created for Queries and Debate for online tutorials on each topic where students are encouraged to participate, send responses and discus set questions.

The material for each topic includes a Power-Point Presentation prepared by the teachers to serve as a guide, in which some aspects of the information must be completed by consulting the references that are sometimes to be found in the presentation itself as links to web pages. The queries, and answers to the questions and simple exercises set in the presentations are discussed in the Debate and Queries forum designed for that purpose. Also, students must perform the learning activities listed below:

\section{A. Guided Projects}

The Learning Guide for each topic contains the instructions for several small projects in accordance with the aims of the topic. Included are the deadlines and ways of presenting the tasks, content and instructions, the estimated work time and assessment criteria. These Projects (see Table I) may include information searches, writing a report or a PowerPoint Presentation or problem-solving and the application or programming of some algorithm. They are small projects that require about four hours' work (which makes the student see it as a feasible task) and approximately one a week has to be completed.

The Moodle Assignment resource is used to manage the deliverables and enable students to upload files.

Project GP1.1 can be taken as an example. A report must be made of an ancient numbering system to be chosen from: Babylonic, Egyptian, Attic Greek, Ionic, Mayan and the ancient Chinese system. Fig. 1 shows the description that enables the student to proceed to the relevant task.

\section{B. Basic Quizzes}

For every topic, students must respond to the questions in one or two Basic Quizzes (BQ). Completing these quizzes is a learning activity that is rewarded in the assessment by $2 \%$ of the final mark for each one. Each BQ has twenty multiple choice questions and is completed interactively online using the Moodle platform. Students have a few days to complete 


\begin{tabular}{|c|c|}
\hline Estimated time & 4 hours \\
\hline Deadline & Ends 8 March at 23:00 \\
\hline Form of submission & Word document (maximum 4 pages) \\
\hline Report content & $\begin{array}{l}\text { 1. Historical context. } \\
\text { 2. Detailed description of the chosen system, } \\
\text { with examples of how to write numbers } \\
\text { (compulsory examples: write } 1524 \text { and } \\
\text { the number formed with the last three } \\
\text { digits of the writer's ID card). } \\
\text { 3. Formulation of the algorithms for adding } \\
\text { and multiplying in the chosen system } \\
\text { (compulsory example: multiply by } 25 \\
\text { the number formed by the first three } \\
\text { non-zero digits of the writer's ID card). } \\
\text { 4. References used and time spent. }\end{array}$ \\
\hline Weighting & $5 \%$ of the final mark for the subject \\
\hline
\end{tabular}

Fig. 1. Description of the Project GP 1.1.

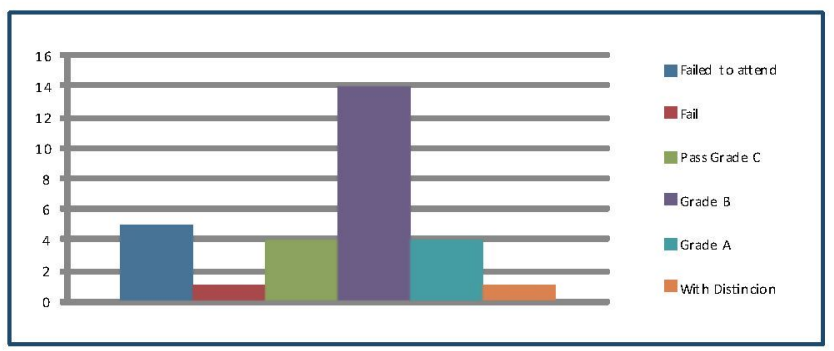

Fig. 2. Academic Results 2009-10.

the question paper at their convenience. They are allowed two attempts (with a twenty minute time limit for each one) and the attempt with the highest number of correct answers will be taken as valid. As submitting the completed question paper is conceived as a learning exercise, the corrected document is shown with feedback to explain the wrong answers. So, on the second attempt, when the student has a different BQ, but linked to the same learning outcomes, they will have the opportunity to correct their mistakes.

\section{End-of-Topic Quizzes}

At the end of each topic all students must complete an End-of-Topic Quiz (ETQ) while simultaneously connected online, with ten multiple choice questions. This question paper is also corrected automatically after submission, but in this case students only have one opportunity and there is no feedback. The summative assessment component of ETQ is greater than that of the $\mathrm{BQ}$, but the formative component is less.

\section{Assessment ModeL}

The assessment of HA subjects is completely online with a continuous assessment model that includes formative and summative assessment and does not include any face-to-face test. Although this may seem surprising, it is something that has been implemented for some time at some universities In [18] a piece of research is presented on the assessment methods used for online Mathematics courses at different universities. Among other things, it concludes that there are a large percentage of courses with $100 \%$ online assessment
TABLE II

SATISFACTION SURVEY 2009-10: AVERAGE SCORES OUT OF A MAXIMUM OF 5

\begin{tabular}{|l|l|l|l|l|l|}
\hline Topics & T. 1 & T. 2 & T. 3 & T. 4 & Average \\
\hline Content & 4.2 & 4.0 & 4.1 & 4.2 & 4.125 \\
\hline Material & 4.0 & 3.6 & 3.6 & 3.9 & 3.775 \\
\hline Presentation & 4.1 & 4.1 & 4.0 & 4.0 & 4.05 \\
\hline Tasks & 3.9 & 3.9 & 4.2 & 3.9 & 3.975 \\
\hline Question papers & 4.2 & 4.0 & 4.1 & 4.0 & 4.075 \\
\hline Assessment & 4.2 & 4.4 & 4.4 & 4.4 & 4.35 \\
\hline
\end{tabular}

where greater importance is placed on the formative assessment than the summative one

The authentication protocols to access the subject do not let any agreed personality theft be detected. However, the risk of any assessment activities being performed by another student is small, bearing in mind that it is a very specific subject with few students, and that there are many very distinct assessment activities, each of which has a very small weighting in the final mark.

The first year's experience has enabled the validity of the model to be tested, from which it was found advisable to slightly lower the percentages of the final mark assigned to the different learning activities.

Some activities have been customised for example, by executing certain algorithms with input data that are linked to the student's ID card number.

The Basic Quizzes are different for every student while the End-of-Topic Quizzes, which are the same for everybody and are done simultaneously, have the questions in a different order with the options shuffled.

To favour formative assessment, the student is given the details of the assessment rubric for each activity and in addition receives the corrected task in a very short space of time. Practically every week the student knows the mark for two activities, which acts as a stimulus to their everyday work routine.

The final percentage of the final mark for each kind of activity is as follows:

1) Guided Projects: $58 \%$ (the mark for each project counts for $3 \%$ to $9 \%$ of the final mark for the subject).

2) Participation in the queries and debate forum: $8 \%$.

3) Basic Quizzes: 14\%.

4) End-of Topic Quizzes: $20 \%$.

In order to pass the subject the student must achieve an overall 5 out of 10 for all the activities and achieve a minimum mark for each topic.

\section{RESUlts AND CONCLUSION}

The HA teachers positively evaluate the experience and are of the opinion that the subject meets the foreseen expectations, provides a fairly adequate panoramic view and builds the foundations for the basic concepts of computability. Moreover, the nature of the content and its cultural, historical and humanistic outlook make it particularly suitable for e-learning 
and has enabled us to acquire online teaching skills that will be useful for other subjects.

Since the online choice widens the spectrum, we managed to get students much more interested in the subject and the relationship with them was very good as they showed reasonably active participation, although it meant more time on the part of teaching staff than was initially foreseen.

The academic results of the first online experience (Fig. 2) were satisfactory and better than those obtained in the previous experience of the subject taught face-to-face: of the 29 students enrolled, 23 passed the subject with reasonably good marks, while the rest dropped out and failed to do the set activities before the end of the course.

The work times stated by students for the activities performed fitted in reasonably with what was estimated.

The students' level of satisfaction (see Table II) was also the highest of the online experience. In similar surveys carried out in the face-to-face experience, the average scores for all the sections in Table II were below 4 .

Future planned lines of work are to set up online mechanisms for collaborative learning and export some of the resources used in this subject to others taught face-to-face.

\section{REFERENCES}

[1] G. Holton, Introduction to Concepts and Theories of Physical Science. Reading, MA, USA: Addison-Wesley, 1962.

[2] R. Peña Marí, De Euclides a Java. Historia de los Algoritmos y de los Lenguajes de Programación. Madrid, Spain: Nivola, 2006.

[3] M. Barceló, Una Historia de la Informatica, Madrid, Spain: Editorial UOC, 2008.

[4] M. Riesco and A. Cernuda, "Incorporación de la historia de la informática a los planes de estudios de informática," in Proc. 15th Jomadas Enseñanza Univ. Inf., 2009, pp. 159-166.

[5] List of Courses on the History of Computing. (2011) Warwick University, Coventry, U.K. [Online]. Available: http://www.dcs.warwick.ac.uk/ mck/HoC_Courses.html

[6] Asignatura: Historia de la Ingenieria, (2012, Feb. 1). Univ. Autónoma Madrid, Madrid, Spain, [Online]. Available: http://arantxa.ii.uam.es/ $\sim$ alfonsec/curso2t.htm

[7] Seminario de Historia de la Matemática Universidad Complutense de Madrid. (2012, Feb. 1) [Online]. Available: http://www.mat.ucm.es/shm

[8] M. Area, “Qué aporta Internet al cambio pedagógico en la educación superior?" in Proc. Actas 3rd Congreso Int. Comutn., Technol. Educ., 2000, pp. 128-135.

[9] C. Steegmann, M. A. Huertas, A. Juan, and M. Prat "E-learning de las asignaturas del ámbito matemático-estadístico en las universidades españolas: Oportunidades, retos, estado actual y tendencias," Revista Univ. Soc. Conocimiento, vol. 5, no. 2, pp. 1-14, 2008.

[10] Oferta Global de Libre Elección por Telenseñanza. $\quad(2012$ Feb. 1). U.P.M., Madrid, Sapin [Online]. Available: http://www.upm.es/institucional/

Estudiantes/OrdenacionAcademica/LEGlobal/online

[11] Moodle (2012, Feb. 1) [Online]. Available: http://moodle.org
[12] P. Canto, I. Gallego, J. Manuel, J. Mora, A. Reyes, E. Rodríguez, K. Sanjeevan, E. Santamaria, and M. Valero, "Cómo usamos Moodle en nuestras asignaturas adaptadas al EEES," IEEE Revista Iberoamericana Technol. Aprendizaje, vol. 5, no. 3, pp. 75-85, Sep. 2010.

[13] M. T. Carracedo, C. Pérez, P. Ramírez, and B. Salazar, "Implantación coordinada del entorno virtual moodle y su utilización en la escuela universitaria de informática de la universidad politécnica de madrid," in Proc. Jomadas Int. Innov. Educ, 2009, pp. 906-915.

[14] M. T. Pérez Rodríguez, Innovación en Docencia Universitaria con Moodle. Casos Prácticos. Alicante, Spain: ECU, 2009.

[15] M. Davis, The Universal Computer. The Road from Leibniz, to Turing. New York, USA: Norton, 2000.

[16] N. Martí, M. Palomino, and J. A. Verdejo, Introducción a la Computación. Madrid, Spain: Anaya, 2005.

[17] Experto en Algorítmica Aplicada a la Empresa y a la Industria. (2012, Feb. 1) [Online]. Available: http://www.eui.upm.es/node/947

[18] S. Trenholm, "An investigation of assessment in fully asynchronous online math courses," Int. J. Educ. Integr., vol. 3, no. 2, pp. 41-55, 2007. 